\title{
Original
}

\section{Radiation Sterilization of the Crude Drug "Glycyrrhiza"}

\author{
SYOJIRO KIMURA ${ }^{1}$, MEIKO TAIMATSU ${ }^{1 *}$, NOBUYOSHI KODANI ${ }^{2}$, \\ TOKUHIRO OHNISHI ${ }^{3}$ AND SHINICH OKAMOTO ${ }^{3}$
'Osaka University of Pharmaceutical Sciences, 4-20-1, Nasahara, Takatsuki-shi, Osaka
569-11, Japan, '2Nippon Boehringer Ingelheim, 103, Takada Yato, Kawanishi-shi, Hyogo 666-01, Japan, and ${ }^{3}$ Research Institute for Advanced Science
and Technology, Osaka Prefecture University, 1-2,
Gakuen-cho, Sakai-shi, Osaka 593, Japan

Received 17 February 1997/Accepted 16 May 1997

\begin{abstract}
The microbial contamination levels of fifteen crude drugs "Glycyrrhiza", which had been harvested in and imported from China and Russia, and their radiation sensitivities were investigated. Specified indicator microorganisms such as Escherichia coli, Staphylococcus aureus and Pseudomonas aeruginosa were not detected, and the number of bacteria and fungi adhering to those drugs were in the range $10^{3}-10^{5}$ cells $/ g$ and $10^{2}-10^{5} \mathrm{spores} / \mathrm{g}$, respectively. Those contamination levels were higher than values of the microbial limits of natural raw materials given in The United States Pharmacopoeial Forum (1992). The average of $D_{10}$ value as radiation sensitivity of bacteria and fungi to gamma rays were 2.2 and $0.98 \mathrm{kGy}$, respectively. From these values, the survival doses (SD) required to attain the definitive microbial limits (bacteria, $<20$ CFU/g or ml; fungi, $<10 \mathrm{CFU} / \mathrm{g}$ or $\mathrm{ml}$ ) were calculated to be $7.5 \mathrm{kGy}$ and $2.7 \mathrm{kGy}$. These SD values are sufficiently lower than the dose of $10 \mathrm{kGy}$ allowed for food irradiation. On the other hand, the quality of Glycyrrhiza powder irradiated up to $\mathbf{3 0}$ kGy passed the "Crude Drugs Test" prescribed in The Japanese Pharmacopoeia Thirteenth Edition.
\end{abstract}

Key words : Radiation sterilization/Pharmaceuticals/Gamma-ray irradiation/Crude drugs/Microbial contamination.

\section{INTRODUCTION}

In every country, not only pharmaceuticals contaminated with pathogenic microorganisms, but also those likely to be contaminated have been prohibited to be sold, imported or produced. Recently, international efforts have been made to decrease the number of microorganisms adhering to the nonsterile pharmaceutical products in order to ensure their quality, safety and stability to the highest degree possible.

In The Japanese Pharmacopoeia Thirteenth Edition (JP13, 1996), definitive microbial limits are given for specified indicator microorganisms, such as E. coli, $S$. aureus and Salmonera species, in several items, i.e., Magnesium Stearate, Lactose, Lactose Anhydride, Crystalline Cellulose, Cellulose Powder and Ipecac

${ }^{*}$ Corresponding author. Tel and Fax: +81-726-90-1042.
Syrup (JP13,1996).

On the other hand, guidelines for definitive microbial limits of nonsterile pharmaceutical products are given in the United States Pharmacopoeial (USP) Forum (1992). If the standards of these guidelines are to be incorporated into The Japanese Pharmacopoeia in the near future, some measures would be necessary to sterilize many pharmaceutical materials. In fact, Yokoyama et al. (1996) reported that microbial contamination levels were very serious, particularly in crude drug materials and their preparations, and that the situation had not recognizably improved, even after Good Manufacturing Practice (GMP) had been promulgated and become firmly established in Japan. In some foreign countries, specified indicator microorganisms such as $E$. coli and $P$. aeuruginosa were also detected in many crude drugs (Faver, 1992; Sincolle et al., 1987). 
In Japan, the method of using ionizing radiation has not been applied in the practical sterilization of pharmaceuticals. However, it is a promising method, and many reports have been published about the effects and application of irradiation (Dam et al., 1990; Kimura et al., 1993; Ohnishi et al., 1993; Ohnishi et al., 1994; Reid, 1995; Wu et al., 1995; Zegota et al., 1995).

In this work, we investigated the microbial contamination levels of the commercially available crude drugs "Glycyrrhiza", their radiation sensitivities, and the radiation doses necessary to satisfy the guidelines of the USP Forum.

\section{MATERIALS AND METHODS}

\section{Samples}

Eight fine and seven coarse powder samples of Glycyrrhiza made in China and Russia were purchased in Osaka and Nara Prefecture. They were of the genus Glycyrrhizae glabla L.var. glandulifera Reg et Herd, Glycyrrhiza uralensis Fisch.et DC, and Glycyrrhiza echinate.

\section{Gamma-ray irradiation}

Specimens for gamma-ray irradiation were packed in a polyethylene bag. The bag was sealed and set in a source vessel of $881 \mathrm{TBq}{ }^{60} \mathrm{Co}$ at Research Institute for Advanced Science and Technology, Osaka Prefecture University. Irradiation conditions were as follows; dose range, from 0.5 to $30 \mathrm{kGy}$; temperature, $25 \pm 1^{\circ} \mathrm{C}$.

\section{Trials to decide the best pretreatment for count- ing microorganisms}

To find the elution which gives the highest count of microorganisms from Glycyrrhiza powder, we conducted pretreatment trials using two suspension agents, saline only and saline with $0.1 \%(\mathrm{v} / \mathrm{V})$ Tween 80 , and three apparatuses for shaking, an automixer, a homogenizer and a supersonic-wave generator. Details of the trial methods using these apparatuses were as follows: 1) A powder sample of $0.5 \mathrm{~g}$ was added to the suspension of $10 \mathrm{ml}$ and mixed together by the automixer for $1 \mathrm{~min}$; 2) A powder sample of 2.5 $\mathrm{g}$ was added to the suspension of $50 \mathrm{ml}$ and homogenized together for $3 \mathrm{~min}$, at 10,000 rpm; and 3) A powder sample of $0.5 \mathrm{~g}$ was added to the suspension of $10 \mathrm{ml}$ and shaken together by supersonic waves for $3 \mathrm{~min}$. As shown in Fig. 1, the highest count of microorganisms was obtained with an addition of Tween 80 to saline and shaking with supersonic waves. Therefore, such pretreatment conditions were chosen and used in this study.

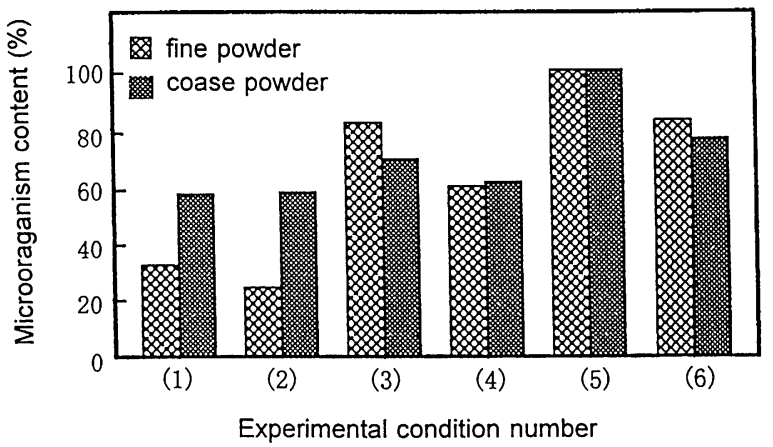

FIG. 1. Comparison of the amounts of microorganisms detected by six methods for pretreatment. (1) Suspension agent, saline with an additon of Tween 80; shaking method, automixer. (2) Suspension agent, saline; shaking method, automixer. (3) Suspension agent, saline with an additon of Tween 80; shaking method, homogenizer. (4) Suspension agent, saline; shaking method, homogenizer. (5) Suspension agent, saline wiht an additon of Tween 80; shaking method, supersonic waves. (6) Suspension agent, saline; shaking method, supersonic waves.

\section{Microbial tests}

Total amounts of bacteria and fungi were determined by a plate agar method with Soybean Casein Digest (SCD) Agar medium and Glucose Peptone (GP) Agar, respectively. The specified microorganisms were cultivated in particular with respective media: MacConkey Agar for E. coli, Mannitol Salt Agar for $S$. aureus and Cetrimide Agar for $P$. aeruginosa. These plates were incubated for $5 \mathrm{~d}$ at 30 or $37^{\circ} \mathrm{C}$ for the specified bacteria and other bacteria, and for $7 \mathrm{~d}$ at $25^{\circ} \mathrm{C}$ for fungi.

Fungi were classified into five genera particularly important for the crude drugs, namely Aspergillus and Penicillium, osmophilic fungi, fiverphilic fungi, Denteromycotina, and Ascomytina, and were counted in the culture media of Czapek-Dox, 40\% (w/v) Sucrose Czapek-Dox Agar, Cellulose Agar, Potato Carrot Agar, and Oatmeal Agar, respectively.

\section{Determination of water content}

The water content of the powder samples were determined by the Karl-Fischer method with a Model MKS-1s Karl-Fischer moisture meter of Kyoto Electronics Co. (Kyoto).

\section{Quality test of crude drugs}

Quality tests were carried out for one kind of fine powder Glycyrrhiza out of eight. Samples irradiated by gamma-rays of $30 \mathrm{kGy}$ and non-irradiated were tested by "Crude Drugs Test" described in JP13, and their qualities were compared before and after irradiation. 


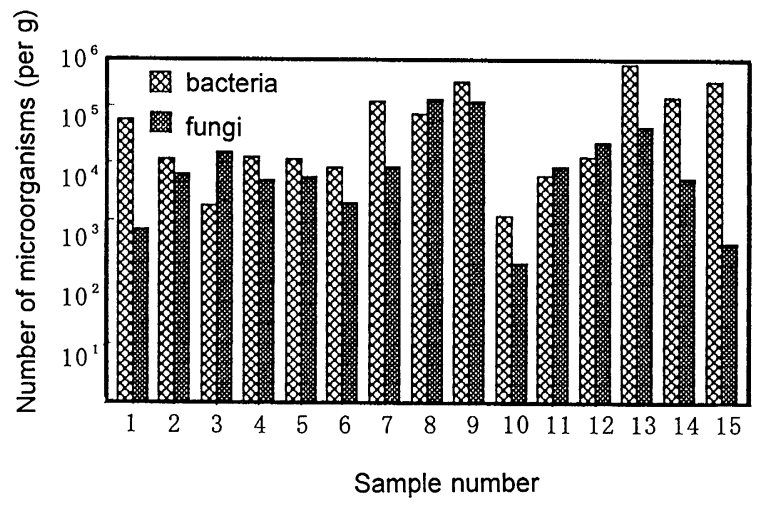

FIG. 2. Number of bacteria and fungi adhering to crude drugs.

\section{RESULTS AND DISCUSSION}

\section{Microbial contamination of crude drug "Glycyr- rhiza"}

No specified indicator microorganisms were found in the fifteen samples of drugs. As shown in Fig. 2, the numbers of bacteria and fungi adhering to drugs were determined to be in the range from $10^{3}$ to $10^{5} \mathrm{cell} / \mathrm{g}$ and from $10^{2}$ to $10^{5} \mathrm{spores} / \mathrm{g}$. These values were much larger than the numbers regulated by the USP Forum. If the limits in Japan are to be set equal to the values of the USP Forum, it would be necessary to employ some sterilization treatment.

\section{Radiation sensitivity of contaminated microor- ganisms}

Survival curves of microorganisms are shown for the four samples in Fig. 3. The radiation resistance of bacteria is higher than that of fungi in all samples. In general, the survival curve for a genus is sigmoidal or exponential, but the patterns of survival curves of Glycyrrhiza were not always simple as those shown in Fig. 3. It is considered that the reason for this is that Glycyrrhiza powder samples were contaminated by several kinds of microorganisms with various radiation sensitivities possibly originating from soil.

The $D_{10}$ values were obtained from the gradient of the linear portion of each survival curve. The Survival Dose value ( $S D$ value), that is, the required dose for decreasing the number of contaminated microorganisms to the targeted limit is calculated from the following formula:

SD value $=D_{10} \times \log \left(N_{0} / N_{S A L}\right)$

where $N_{0}$ is the number of microorganisms before irradiation, $N_{S A L}$ is the targeted limit value for the contamination of microorganisms. Table 1 shows the $D_{10}$ values and SD values. The average $D_{10}$ value for contaminated microorganisms in fifteen kinds of sample were $2.2 \mathrm{kGy}$ for bacteria and $0.98 \mathrm{kGy}$ for fungi; the average SD values were $7.5 \mathrm{kGy}$ for bacteria and 2.7 kGy for fungi. Here, the $N_{S A L}$ values were taken from the value after completion of the decontamination process of microorganisms as listed in the guidelines in the USP Forum (1992) (Bacteria, $<20 \mathrm{CFU/g}$ or $\mathrm{CFU} / \mathrm{ml}$; fungi, $<10 \mathrm{CFU} / \mathrm{g}$ or $\mathrm{CFU} / \mathrm{ml}$ ). Excepting

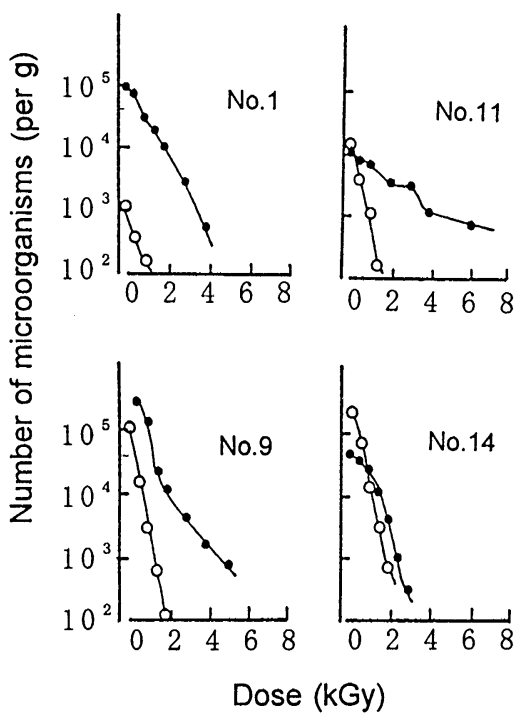

FIG. 3. Survival curves of bacteria and fungi adhering to Glycyrrhiza. Symbols: $\bigcirc$, bacteria; $\bigcirc$, fungi.

TABLE 1. $D_{10}$ values and SD values for microorganisms adhering to Glycyrrhiza.

\begin{tabular}{ccccc}
\hline \multirow{2}{*}{$\begin{array}{c}\text { Sample } \\
\text { no. }\end{array}$} & \multicolumn{2}{c}{ Bacteria } & \multicolumn{2}{c}{ Fungi } \\
\cline { 2 - 5 } & $\begin{array}{c}D_{10} \text { value } \\
\text { (kGy) }\end{array}$ & $\begin{array}{c}\text { SD value } \\
\text { (kGy) }\end{array}$ & $\begin{array}{c}D_{10} \text { value } \\
\text { (kGy) }\end{array}$ & $\begin{array}{c}\text { SD value } \\
\text { (kGy) }\end{array}$ \\
\hline 1 & 3.4 & 9.1 & 1.1 & 3.5 \\
2 & 1.8 & 7.8 & 0.8 & 3.4 \\
3 & 2.9 & 8.2 & 1.0 & 2.5 \\
4 & 2.7 & 8.0 & 1.1 & 3.3 \\
5 & 2.1 & 6.3 & 0.8 & 2.4 \\
6 & 2.1 & 9.7 & 0.7 & 2.7 \\
7 & 2.4 & 7.2 & 1.2 & 3.5 \\
8 & 2.1 & 7.9 & 0.6 & 2.6 \\
9 & 1.9 & 7.7 & 1.1 & 3.2 \\
10 & 1.8 & 3.5 & - & - \\
11 & 2.4 & 10.4 & 1.4 & 2.5 \\
12 & 2.1 & 6.3 & 0.9 & 3.2 \\
13 & 2.1 & 8.4 & 0.7 & 2.2 \\
14 & 2.1 & 4.5 & 1.0 & 3.4 \\
15 & 1.9 & 6.6 & 1.3 & 2.7 \\
Ave. & 2.2 & 7.5 & 0.9 & 2.7 \\
\hline
\end{tabular}

${ }^{a}$ The definitive microbial limits (bacteria, $<20 \mathrm{CFU} / \mathrm{g}$ or $\mathrm{CFU} / \mathrm{ml}$; fungi, $<10 \mathrm{CFU} / \mathrm{g}$ or $\mathrm{CFU} / \mathrm{ml}$ ) listed in the gidelines of the USP Forum. (1992). 
sample no.11, the SD values were sufficiently lower than the dose of $10 \mathrm{kGy}$ allowed for food irradiation (WHO Technical Report, 1981). If specified indicator microorganisms had actually been detected in the present samples, they would be perfectly eradicated in the above irradiation conditions, because the radiation sensitivity of these bacteria are very high. For example, the $D_{10}$ values of $S$. auresus, $P$. aeruginosa, $E$. coli and $S$. typhimurium are $0.2,0.1,0.1-0.5$ and $0.2-$ 0.8 kGy, respectively.

It is to be noted that the radiation sensitivity of microorganisms is affected by the water content of the sample. In general, the water content of the dry sample of crude drugs was about $5 \%(\mathrm{w} / \mathrm{w})$. Survival curves of microorganisms adhering to Glycyrrhiza with a water content of $15 \%(\mathrm{w} / \mathrm{w})$ and $30 \%(\mathrm{w} / \mathrm{w})$ were measured, and were compared with those of the dry samples in Fig. 4. As the result, the survival curve of fungi was found to be exponential at all levels of water content. On the other hand, the survival curves of bacteria at the water content of $5 \%(\mathrm{w} / \mathrm{w})$ and $15 \%(\mathrm{w} / \mathrm{w})$ were sigmoidal functions, and that of $30 \%(\mathrm{w} / \mathrm{w})$ was an exponential function. For both fungi and bacteria, radiation sensitivity was higher with a higher water content. The reason for this is considered to be the indirect action of radicals in $\mathrm{H}_{2} \mathrm{O}$ in the microbial cell.

\section{Effect of water content on storage}

The number of microorganisms adhering to Glycyrrhiza powder (the water content of $5 \%, \mathrm{w} / \mathrm{w}$ ) did not increase during storage before and after irradiation. However, the number of bacteria and fungi might be suddenly increased by the presence of a little water. Therefore, the change with time of the num- ber of microorganisms adhering to non-irradiated samples nos. 9, 12 and 14 were measured, and are shown in Fig. 5. In this figure, "direct" (closed symbols) and "indirect" (open symbols) refer to the samples prepared with an adjusted water content of $30 \%$ $(\mathrm{w} / \mathrm{w})$ and the samples prepared to make its water activity to being 1 in atmosphere, respectively. The results show that the number of bacteria increases after storage of 1 or $2 \mathrm{~d}$ and reaches a constant between 4 and $10 \mathrm{~d}$. The tendency of the increase in the num-

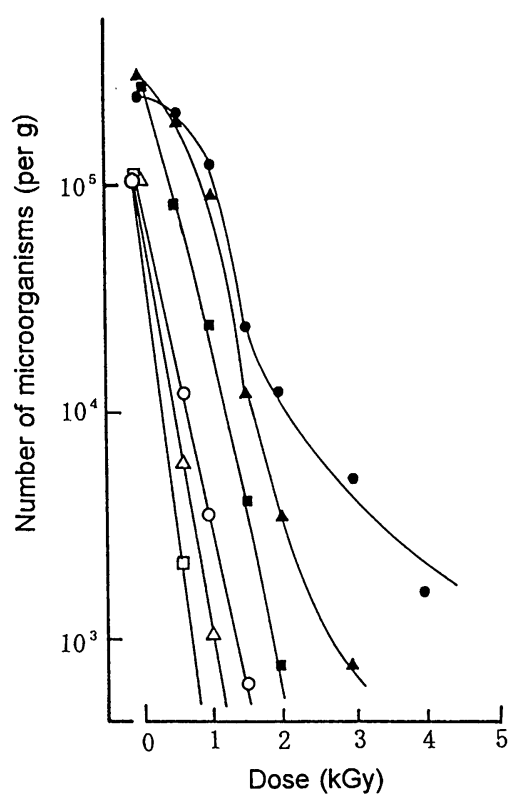

FIG. 4 . Radiation sensitivities of microorganisms in Glycyrrhiza powder with various water content values of $5.5 \%$ (circles), 15\% (triangles) and 30\% (squares). Closed and open symbols are for bacteria and fungi, respectively.
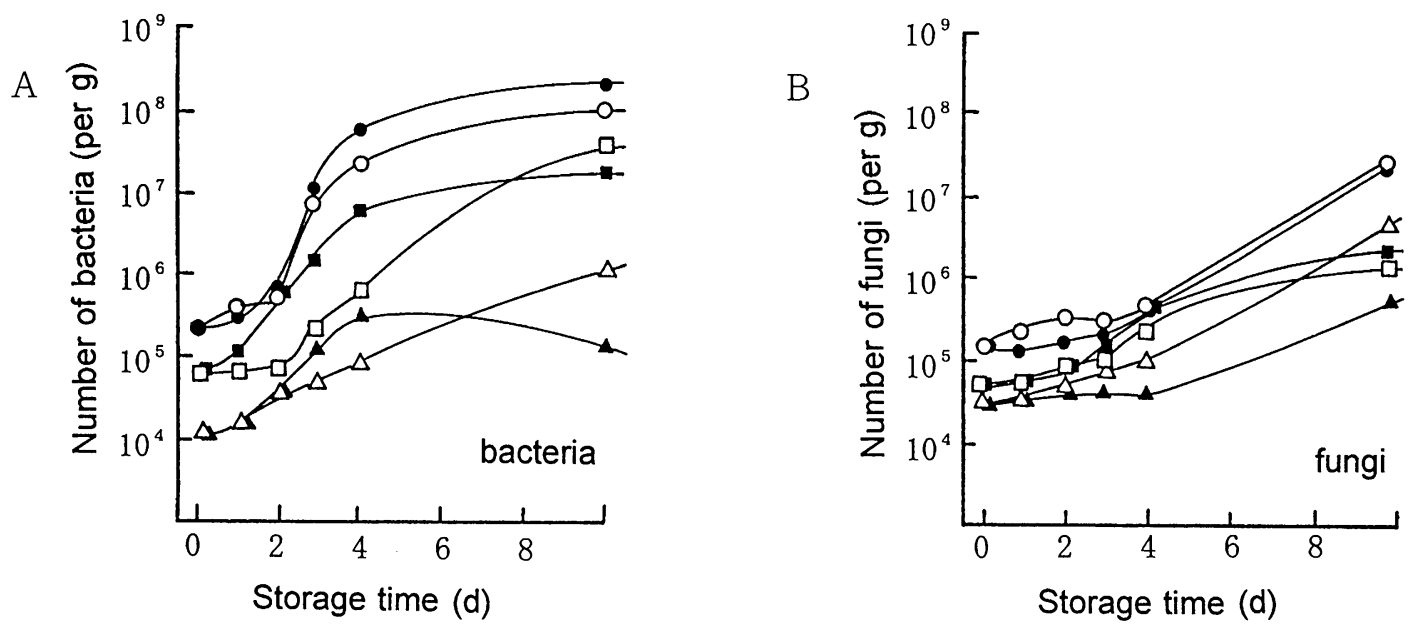

FIG.5. Change in the number of bacteria $(A)$ and fungi $(B)$ adhering to Glycyrrhiza during storage before irradiation for sample no.9 (circles), no.12 (triangles) and no.14 (squares). Closed and open symbols are for direct and indirect water content preparations, respectively. 
ber of bacteria was almost the same for the "direct" and "indirect" samples. The increase in the number of fungi was smaller than that of bacteria, but the former showed an increase by one to two orders of magnitude after $10 \mathrm{~d}$.

On the other hand, the above samples irradiated by gamma-rays of $10 \mathrm{kGy}$ did not show the presence of microorganisms. In the case of $5 \mathrm{kGy}$ irradiation, microorganisms were not detected in sample no.14, and the results for samples nos. 9 and 12 are shown in Fig. 6. The increase of microorganisms in irradiated samples was at a slower rate than that in nonirradiated samples.

From the results described in the earlier subsection, it is possible to enhance the radiation sensitivity of microorganisms by increasing the water content of the sample. In this case, however, it is necessary to apply a dry treatment after irradiation to prevent the in-

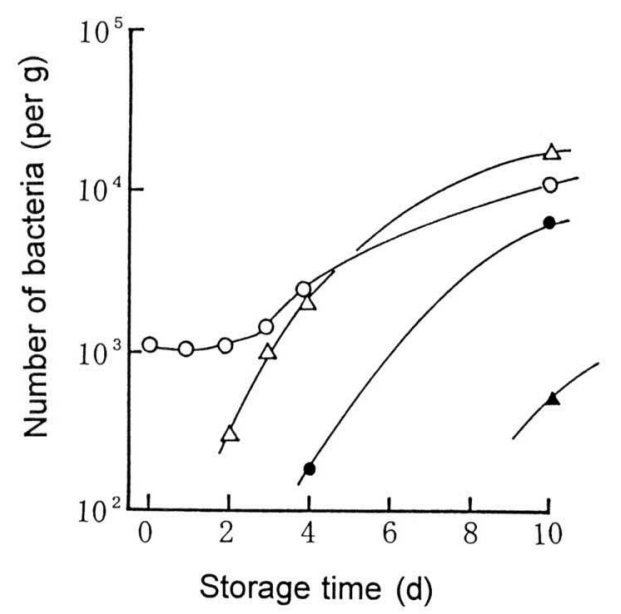

FIG. 6. Change in the number of bacteria adhering to Glycyrrhiza during storage after irradiation for sample no. 9 (circles), no.14 (triangles). Ciosed and open symbols are for direct and indirect water content preparations, respectively. crease of microorganisms during storage.

\section{Radiation sensitivity of fungi}

Metabolic products produced by some kinds of fungi have adverse effects on man. Therefore, detailed genus distributions of fungi were measured and are shown in Fig. 7. In all the samples, contamination levels of the fungi were not the same, but the relative amounts of different genera were almost the same. Results of a further study of the survival curve of each genus as a function of dose are shown in Fig. 8. As results, the forms of the survival curve were diffrent for each genus. $D_{10}$ values of Aspergillus and Penicillium species, osmophilic fungi, fiverphilic fungi, Denteromycotina and Ascomytina were 0.30, 0.48, 0.81, 0.81 and $0.50 \mathrm{kGy}$, respectively. The $D_{10}$ value of total fungi was $0.82 \mathrm{kGy}$. Aspergillus and Penicillium species showed a high radiaton sensitivity. Thus, it is concluded that crude drugs as natural products are contaminated by microorganisms having various sensitivities to gamma-ray irradiation and that the pattern of the survival curve is affected by the ratios of different microorganisms mixed in the sample.

On the other hand, mycotoxins are produced from such species as Aspergillus and Penicillium. Aflatoxin, a kind of mycotoxin, is a carcinogen, and it was reported that some crude drugs were contaminated by this toxin (Roy et al., 1988). The dose required to decompose mycotoxins by gamma-ray irradiation is higher than the sterilization dose of the above microorganisms. Therefore, microorganisms such as Aspergillus and Penicillium species should be sterilized by gamma-ray treatment before mycotoxins are produced.

\section{Quality test of crude drugs}

To study the change in the quality of Glycyrrhiza after irradiation, fine powder sample no. 8 irradiated up to $30 \mathrm{kGy}$ and the same non-irradiated sample were

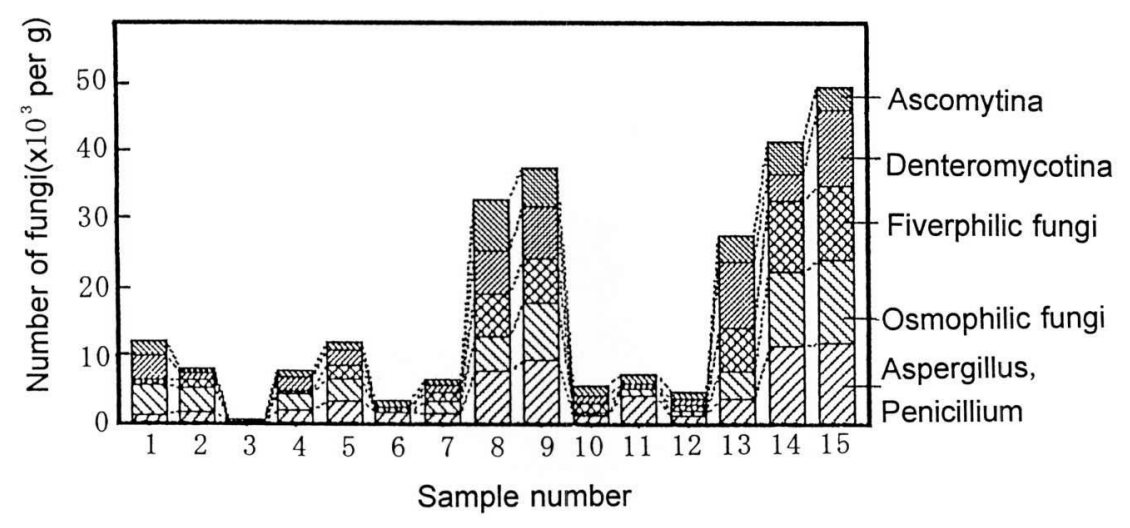

FIG. 7. Relative amounts of each genus of fungi. 
tested by "Crude Drugs Test" in JP13. The dose of 30 kGy is 3 times that of 10 kGy allowed for irradiation. The results are shown together with the standard limits in JP13 in Table 2. The Glycyrrhizin content and the extract content were decreased slightly, and its range was sufficiently within the standard deviation range of the measurement. The values of the irradiated sample did not exceed the standard limit values for Glycyrrhiza. The quality of Glycyrrhiza was not damaged by the dose up to 30 kGy.

\section{REFERENCES}

Dam, A., Gazso, L. G., and Grigorova, P. (1990) Microbiological investigations for radiation treatment of pharmaceuticals. Int. J. Radiat. Appl. Instrum. Part C, 35, 396-399.

Faver, J. (1992) Etude de la contamination micro-

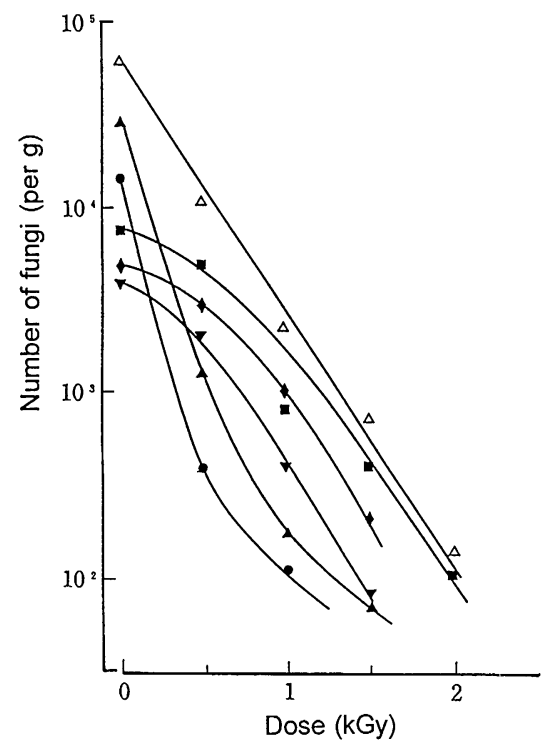

FIG. 8. Survival curve of each genus of fungi. Symbols: $\triangle$, total fungi; $\boldsymbol{O}$, Aspergillus and Penicillium; $\boldsymbol{\Delta}$, osmophilic fungi; $\boldsymbol{\square}$, fiverphilic fungi;

Ascomytina. bienne d'une vingtanine de drogues vegetales. Pharm. Acta. Helv., 67, 250-258.

Kimura, S., Taimatsu, M., Kanbashi, T., Okamoto, S., and Ohnishi, T. (1993) The variations of enzymatic activity of pepsin preparation by gamma irradiation (in Japanese). Radioisotopes, 42, 75-83.

Ohnishi, T., Okamoto, S., Kimura, S., and Kodani, N. (1993) Radio-sensitivities of microorganisms adhering to the crude drug "Glycyrrhizae Radix". Bull. Univ. Osaka. Pref. Ser. B, 45, 93-99.

Ohnishi, T., Okamoto, S., Kimura, S., Taimatsu, M., and Endo, A. (1994) Radiation sensitivity of microorganisms adhering to the crude drugs "Bezoar Bovis" and stability of its main component for gamma-ray irradiation. Bull. Univ. Osaka. Pref. Ser. $B, \mathbf{4 6}, 125-134$.

Reid, B. D. (1995) Gamma processing technology. J. Pharm. Sci. Technol., 49, 83-89.

Roy, A. K., Sinha, K. K., and Chourasia, H. K. (1988) Aflatoxin contamination of some common drug plants. Appl. Env. Microbiol., 54, 842-843.

Sincholle, D., Cotta, M., Guedon, D., and Coll, R. (1987) Plantes medicininales et decontamination. Pharm. Acta. Helv., 62, 14-18.

The Japanese Pharmacopoeia Thirteenth Edition (in Japanese) (1996) Hirokawa, Tokyo.

The United Sates Parmacopoeial Forum (1992) 18, 3596-3600.

WHO Technical Report Series (1981) no. 659.

Wu, J., Zhang, X., Yuan, R., and He, Y. (1995) Radiolysis of herbs. Radiat. Phys. Chem., 46, 275279.

Yokoyama, H., Sakagami, Y., Yamazaki, K., Okamura, T., and Kajimura,'K. (1996) Present status and future subjects of microbiological quality assurance of crude drugs and Chinese traditinal medicines (in Japanese). J. Antibact. Antifung. Agents, 24, 489498.

Zegota, H., Koprowski, M., and Zegota, A. (1995) Effect of gamma irradiation on cefotaxime in the solid state. Radiat. Phys. Chem., 45, 223-229.

TABLE 2. The results of crude drugs test.

\begin{tabular}{lccc}
\hline \multirow{2}{*}{ Item of evaluation } & \multicolumn{3}{c}{ Content (\%, w/w) } \\
\cline { 2 - 4 } & $\begin{array}{c}\text { Non-irradiated } \\
\text { sample }\end{array}$ & $\begin{array}{c}\text { Irradiated } \\
\text { sample (30kGy) }\end{array}$ & $\begin{array}{c}\text { Standard } \\
\text { limit }^{a}\end{array}$ \\
\hline Glycyrrhizin content & 3.98 & 3.87 & $>2.6$ \\
Weigh loss on drying & 7.00 & 6.96 & $<12$ \\
Ash content & 2.89 & 2.89 & $>7.0$ \\
Acid-insoluble ash & 0.09 & 0.05 & $<2.0$ \\
Extract content & 32.0 & 30.0 & $>25$ \\
\hline
\end{tabular}

${ }^{a}$ From JP13 (1996). 